\title{
CALIBRATION OF A FEM MODEL WITH COMPLEX GEOMETRY: THE CASE STUDY OF SANTA MARIA MADDALENA CHURCH IN ISCHIA, ITALY
}

\section{BEATRICE DI NAPOLI ${ }^{1 *}$, MARIA PIA CIOCCI ${ }^{1}$, THOMAS CELANO ${ }^{2}$, PAULO B. LOURENÇO $^{1}$ AND CLAUDIA CASAPULLA ${ }^{3}$}

\author{
${ }^{1}$ Institute for Sustainability and Innovation in Structural Engineering (ISISE), \\ Department of Civil Engineering, University of Minho \\ Campus de Azurém, 4800-058 Guimarães, Portugal \\ e-mail: \{beatrice.dinapoli1992, mariapiaciocci\}@gmail.com,pbl@civil.uminho.pt, www.isise.net \\ (*corresponding author) \\ ${ }^{2}$ Department of Engineering, \\ University of Naples Parthenope \\ Centro Direzionale is.C4, 80143 Napoli, Italy \\ email: thomas.celano@uniparthenope.it \\ ${ }^{3}$ Department of Structure for Engineering and Architecture \\ University of Naples Federico II \\ Via Forno Vecchio, 80143 Napoli, Italy \\ email: casacla@unina.it
}

Keywords: FEM model, calibration, OMA, heritage structures, Baraccato system, modeling

\begin{abstract}
The technology of the Bourbonic casa Baraccata is one of the earliest earthquake resisting systems, used since the 18th century across Southern Italy in response to the disastrous earthquakes that hit the region frequently. The church of Santa Maria Maddalena in Casamicciola Terme, Ischia Island, Italy, represents one of the very rare examples, with a unicity lying on the combination of materials adopted. It presents the regular Bourbonic Baraccato walls in the back portion, and tuff-masonry walls embraced in iron frames in the main body. The paper aims at presenting the development of a 3D Finite Element Model (FEM) calibrated taking advantage of ambient vibration tests performed under operational conditions. Sensitivity analyses allowed to inspect and validate several modeling strategies and explore the relevance of the data still unknown to define a reliable numerical model to perform the study on the seismic behavior of the church of Santa Maria Maddalena.
\end{abstract}

\section{INTRODUCTION}

Historical masonry churches are one of the most seismically vulnerable building typologies which need to be preserved considering their value in cultural heritage. Though several in-situ and numerical investigations have been performed in past studies (for example [1]-[5]), the structural behavior of these buildings is still not fully understood to date. The seismic safety assessment of churches is a very complex task due to the numerous irregularities and 
uncertainties (geometry, mechanical material properties, historic evolution of the structure, etc.). In particular, these buildings can exhibit numerous failures depending on different parameters such as: mass and stiffness distributions, connection among transversal walls, thrusting roofs, masonry qualities, etc. The failure modes observed for these buildings downstream of seismic events can be divided into a limited group of typical failures. For these reasons, historical masonry structures present a high number of challenges in the safety assessment.

Different conservation methodologies are present in the literature to analyze and retrofit historical masonry construction, as evidenced by [6]. The timber-masonry system represents one of the most used reinforcement strategies in Southern Italy since the catastrophic seismic events of the $18^{\text {th }}$ century. The structural performance of the so-called Bourbonic Baraccato system has been studied by [7] and [8], while investigations on similar systems have been carried out by [9]. This construction system is even more interesting in the case of the church of Santa Maria Maddalena in the Ischia Island (Italy), where it was combined with a mixed iron-masonry solution. A first study on this particular church has been carried out by [10], while open issues on the modeling strategies are still worthy to be addressed.

\section{Non-linear analyses are recommended for the evaluation of the structural behavior of these} buildings, requiring a good level of knowledge of the construction such as the mechanical properties of the materials. In common practice, destructive and non-destructive tests can be performed in order to evaluate masonry material properties. In particular, non-destructive tests are mainly used for the evaluation of the elastic properties of the material, such as Young's modulus. Since a calibration number of destructi mechanical properties

limited. Destructive not recommended, not allowe
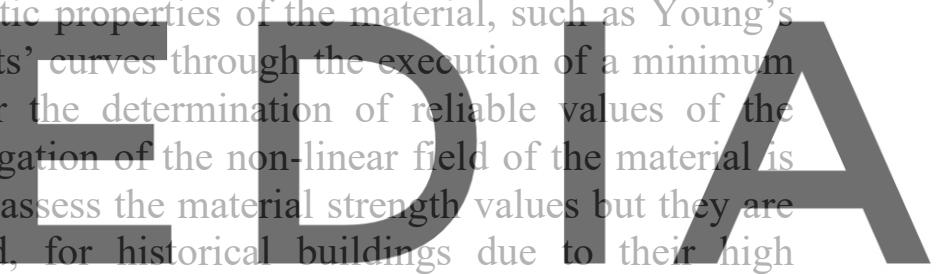

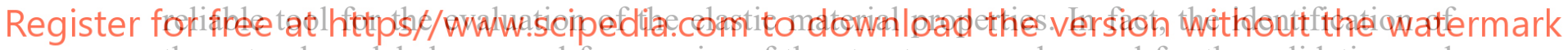
the natural modal shapes and frequencies of the structures can be used for the validation and the calibration of numerical models, in the elastic-field.

This paper presents a methodology for the calibration of a refined numerical model of a case study, the Santa Maria Maddalena church in Ischia, according to the in-situ dynamic identification tests presented by [11]. The post-processing results performed in ARTeMIS environment are presented and compared with the eigenvalue analyses results obtained in the numerical model. Lastly, the description of the calibration procedures, obtained through the comparison of the modal shapes and frequencies of the existing structure and the numerical model, enables the validation of some of the adopted modeling strategies and the updating of the Young's moduli of the masonry walls [12]. In addition, the paper presents final remarks regarding the calibration phase and the experimental campaign.

\subsection{Description of the case study}

Downstream of the moderate seismic event $(\mathrm{Mw}=4.2)$ that hit the Ischia Island on August 21st, 2017, the church of Santa Maria Maddalena in Casamicciola Terme exhibited a relatively low post-seismic damage to the structural system, with distributed crack patterns 
mainly detected in the decorative elements, as evidenced by [11].

The building was re-built at the end of the 19th century, after one of the deadliest earthquakes that stroke the Ischia Island in its history, the Casamicciola Terme earthquake of 1883. The construction was designed with one of the most advanced techniques for the seismic risk mitigation at the time and in compliance with the post-seismic recommendations of the municipalities, the adoption of the Bourbonic Baraccato system.

As sketched in Figure 1, the church is composed by the religious spaces arranged with the typical Latin-cross shaped plan configuration (blue), a two-story back part, which hosts some spaces for the parish's activities and the priest's house (green), and the bell tower located in the north-western corner (red). The front part consists of an almost rectangular footprint of dimensions $39.04 \mathrm{~m} \times 20.72 \mathrm{~m}$ with five different height levels. The maximum heights of the church are $16.32 \mathrm{~m}$ and $22.30 \mathrm{~m}$ for the roof top and the bell tower, respectively. It is important to underline that 6 rows of columns are located along the central nave up to the transept. The church covering is supported by a simple system of Palladian timber trusses, aligned along its longitudinal direction.

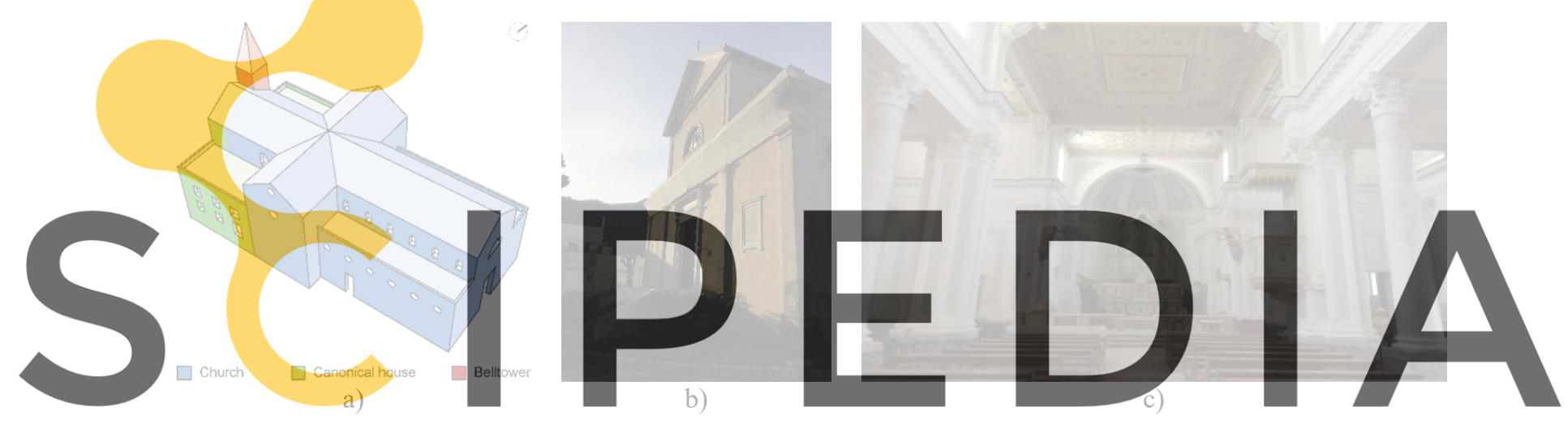

Figure 1: a) Volumetric representation, b) external view of the church, c) internal view of the church Register for free at https//www.scipedia.com to download the version without the watermark

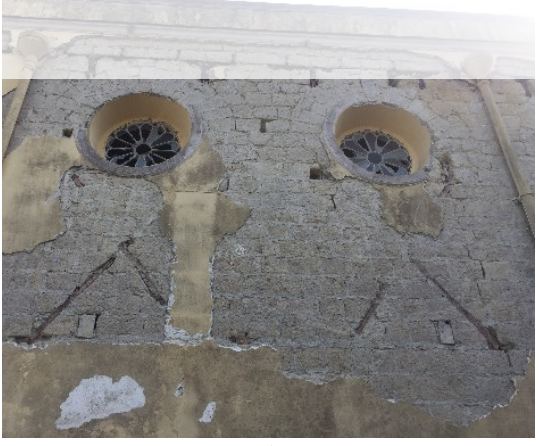

a)

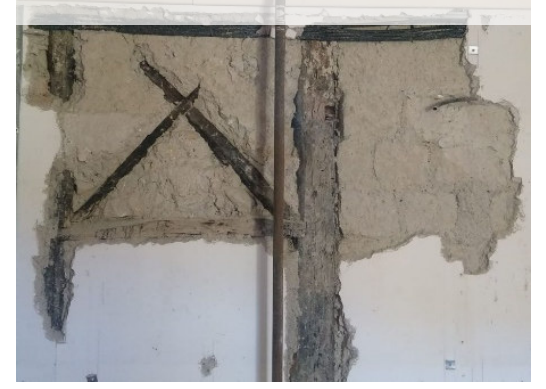

b)

Figure 2: a) Iron-Baraccato wall panel, b) timber-Baraccato wall panel

The particularity of this building is the use of a mixed system for the load-bearing walls, made of Neapolitan yellow tuff blocks and either chestnut timber or iron elements. In the front part, the church is composed by the mixed iron-masonry technology (Figure 2a), with masonry enveloped in two layers of iron frames which are connected transversally through the 
walls thickness. This technology was identified as the so-called 'iron-Baraccato' system for the similarity between the layout of the iron frames and the layout of a regular Baraccato panel ([8], [11]). Some in-situ investigations allowed to identify this layout that is presented in Figure 3. The frames encaging the walls constitute a rigid skeleton whose principal advantage to the structural behavior is the connection that they provide between the various structural units. They primarily assure the connection between orthogonal walls, floors and columns. The use of the iron also in these structural units, indeed, enables a structural continuity of the iron frames of the walls and their metallic elements which connection is easily and effectively resolved. Lastly, the presence of a double layer of iron frames tied with each other provides to the walls a certain level of confinement, which increases the overall strength of each wall section.

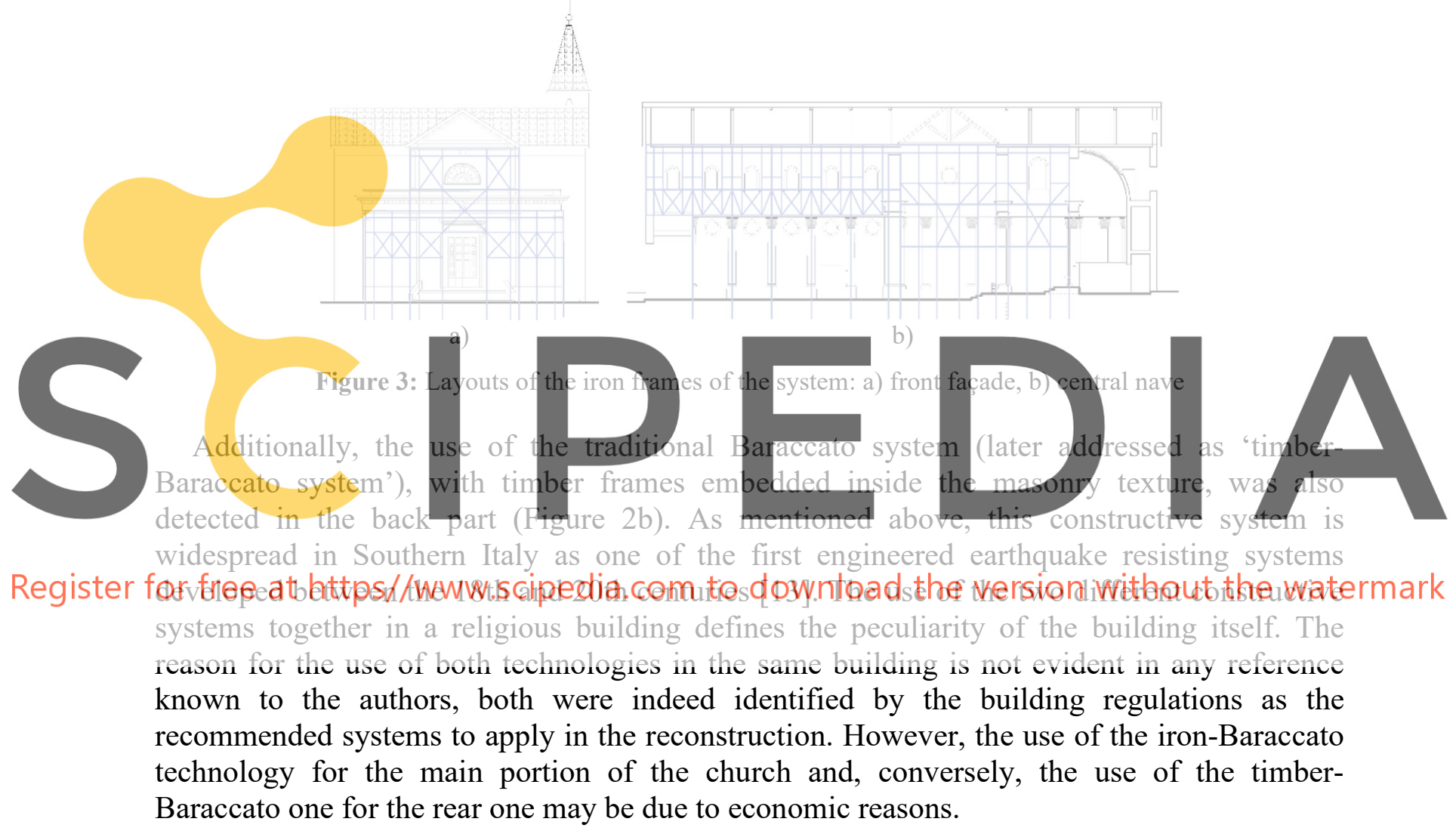

\section{DYNAMIC IDENTIFICATION OF THE CHURCH}

\subsection{In-situ ambient vibration tests}

In-situ ambient vibration tests were performed under operational conditions, under commission of the Campania Regional Directorate for Cultural Heritage (MiBACT), in order to investigate the dynamic response of the structure [11].

Two different test setups were used, with measurement points located at three different levels of the church, as shown in Figure 4. The measurements reported in red color are the ones that were maintained in the same position for the implementation of the two setups, in 
green the ones corresponding to the first setup and in blue to the second setup.

The data were collected using ceramic piezoelectric uniaxial accelerometers with high sensitivity $(10.0 \mathrm{~V} / \mathrm{g})$, low noise $(0.13 \mu \mathrm{g} / \sqrt{\mathrm{Hz}})$, resolution of $10-5 \mathrm{~g} \mathrm{rms}$ and frequency range of 0.1-200 Hz. They were firmly anchored to the church walls by means of metallic plates avoiding damaged zones and plaster detachments, in order to assure good quality readings. The two setups recorded ambient vibrations for a total time of 3600 s with a sampling frequency of $100 \mathrm{~Hz}$. More details can be found in the work of [11].
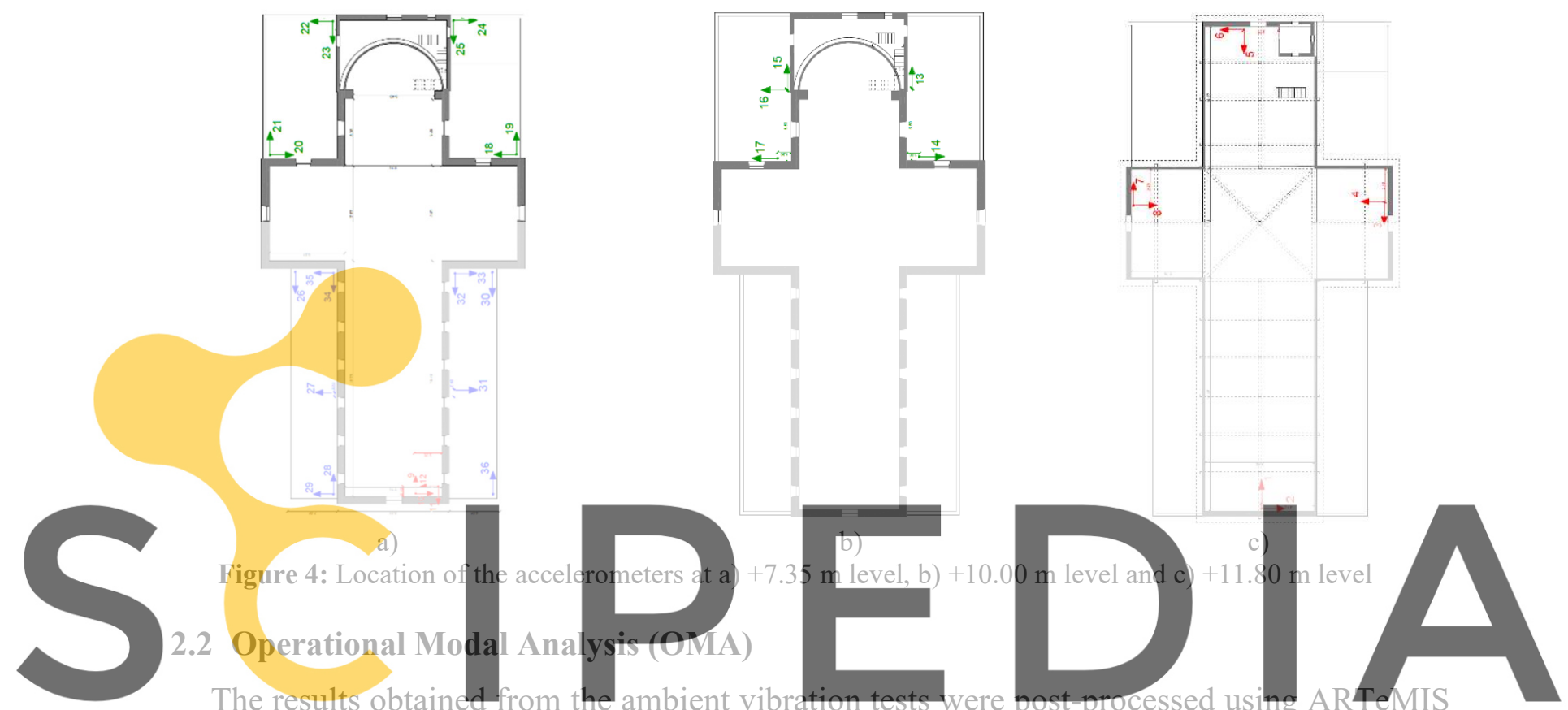

software [14]. The two setups were analyzed both with the Enhanced Frequency Domain

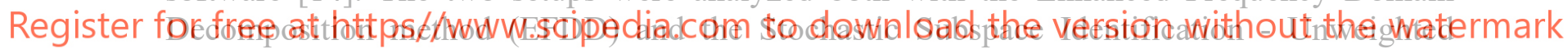

Principal Components Merged Test Setups method (SSI-UPCX). Since more accurate results

were provided by the former method ([10], [11]), only the results obtained by using EFDD are presented in this paper. Figure 5 presents the natural frequencies, modal shapes and damping ratios of the first three modes of vibration which were identified for the structure. In particular, the identified modal shapes can be described as follows:

- $\quad$ Mode I: translational mode in the transversal direction of the church, characterized by major amplitudes of the transept and in-phase displacements between the central nave and the apse walls;

- Mode II: translational mode in the longitudinal direction of the church, characterized by major amplitudes in the central nave and in-phase displacements between the central nave and the apse walls;

- Mode III: mode characterized by the out-of-phase displacements of the longitudinal walls in the transversal direction.

It should be noted that the modal shapes are highly influenced by the geometry implemented in ARTeMIS software, since the representation of the only measured nodes is not enough to clearly understand the effective modes of vibration of the structure. Therefore, the geometrical model of the church was iteratively optimized to compromise between a 
sufficiently detailed representation of the building and a sufficiently simplified geometry, taking advantage of the interpolation functions available in ARTeMIS software that were applied to the non-measured nodes to supply the missing information.

Mode I

Frequency $=2.54 \mathrm{~Hz}$

Damping ratio $=2.23 \%$

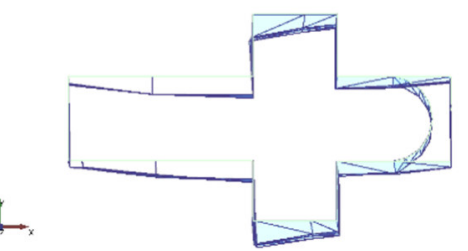

Mode II

Frequency $=3.75 \mathrm{~Hz}$

Damping ratio $=1.43 \%$

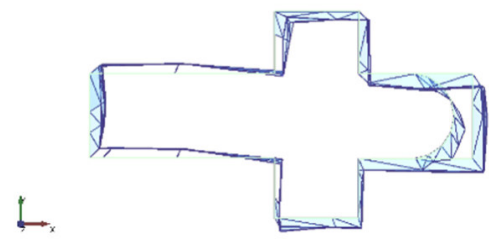

Mode III

Frequency $=4.90 \mathrm{~Hz}$

Damping ratio $=1.21 \%$

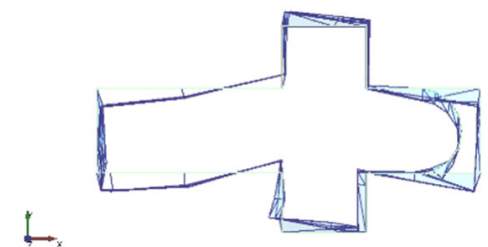

Figure 5: Results obtained by using EFDD method

\section{BRIEF DESCRIPTION OF THE FEM MODEL}

For the structural assessment of the church a FEM model was prepared in Midas FX + and DIANA 10.3 (DIsplacement ANAlyser) [15], representing the full relevant structural characteristics of the building.

An initial tentative model was implemented with the inspected during the calibratid and timber frames of th etc., were represented with 3D beam elements s. The two Baraccato walls typologies were nnou elements with imprinted and embedded 3D beams for the

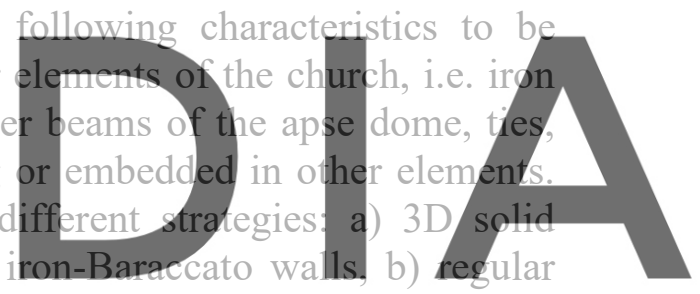
curved shells with imprinted beams for the timber-Baraccato walls. The metallic floor slabs of

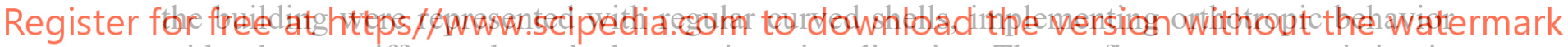
with relevant stiffness along the beam orientation direction. The roofing system, consisting in a non-thrusting timber system composed of king post trusses, was modeled through the application of an equivalent mass at the top of the model distributed along the roof perimeter. Lastly, as first tentative and not to overweigh the complexity of an already size relevant model, the boundary conditions representing the interaction of the church with the soil were set to perfectly fixed conditions. Figure 6 presents a view of the mesh of the numerical model.

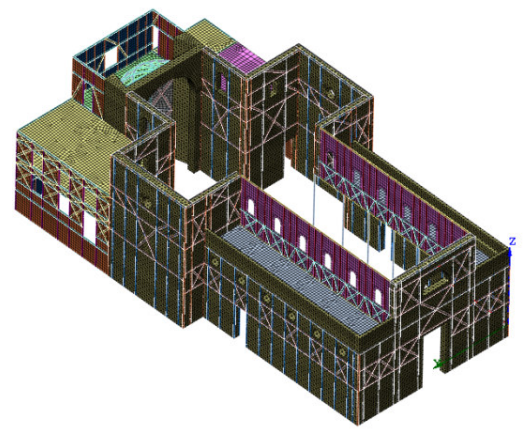

Figure 6: Representation of the 3D FEM model of the church (roof ties omitted) [12] 
As for the mechanical characteristics of the materials found in the church, elastic properties were assigned on the base of the literature and code values. The Young's and shear moduli of the orthotropic material implemented for the floor slabs were assigned with simple engineering calculations based on iron properties assumed from the literature and according to [16]. Lastly, masonry was modeled with non-linear properties assuming parabolic behavior in compression and exponential behavior in tension [15] (Figure 7), with strength values estimated as the minimum values recommended by the Italian code [17], reported in Table 1.

Table 1: Elastic material properties of the materials in the model ([10], [12])

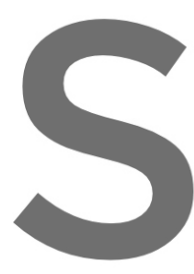

\begin{tabular}{|c|c|c|c|}
\hline \multicolumn{4}{|c|}{ WROUGHT IRON [18] } \\
\hline Material property & Symbol & Value & Units \\
\hline Density & $\rho$ & 7.85 & {$\left[\mathrm{~T} / \mathrm{m}^{3}\right]$} \\
\hline Young's modulus & $\mathrm{E}$ & 154 & {$[\mathrm{GPa}]$} \\
\hline Poisson's ratio & $v$ & 0.3 & {$[-]$} \\
\hline \multicolumn{4}{|c|}{ TIMBER - CHESTNUT [19], [20] } \\
\hline Material property & Symbol & Value & Units \\
\hline Density & $\rho$ & 0.64 & {$\left[\mathrm{~T} / \mathrm{m}^{3}\right]$} \\
\hline Young's modulus & $\mathrm{E}$ & 8000 & {$[\mathrm{MPa}]$} \\
\hline Poisson's ratio & $v$ & 0.3 & {$[-]$} \\
\hline \multicolumn{4}{|c|}{ CONCRETE [21] } \\
\hline Material property & Symbol & Value & Units \\
\hline Density & $\rho$ & 2.4 & {$\left[\mathrm{~T} / \mathrm{m}^{3}\right]$} \\
\hline Young's modulus & $\mathrm{E}$ & 25.3 & {$[\mathrm{GPa}]$} \\
\hline Poisson's ratio & $\mathrm{V}$ & 0.2 & \\
\hline Material property & Symbol & Value & Units \\
\hline Density & $\bar{P}$ & 14 & {$\left[\mathrm{~T} / \mathrm{m}^{3}\right]$} \\
\hline Young's modulus & E & $887 *$ & {$[\mathrm{MPa}]$} \\
\hline Poisson's ratio & v & 0.2 & \\
\hline Compr. strength & $f_{c}$ & 1400 & {$\left[\mathrm{kN} / \mathrm{m}^{2}\right.$} \\
\hline Tens. strength & $\mathrm{f}_{\mathrm{t}}$ & 140 & {$\left[\mathrm{kN} / \mathrm{m}^{2}\right.$} \\
\hline
\end{tabular}

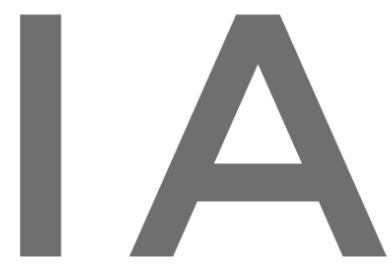

Register for free at https//wWw.s cipged faedeofip] to download? the version without the watermark Tens, tracture energy 23$]$

* Young's modulus obtained through modal calibration

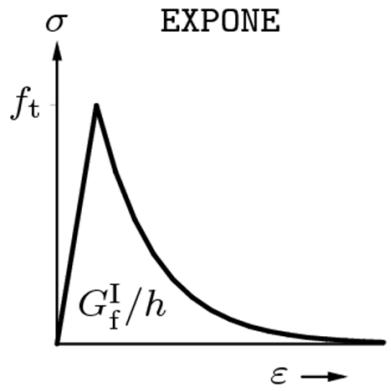

(a)

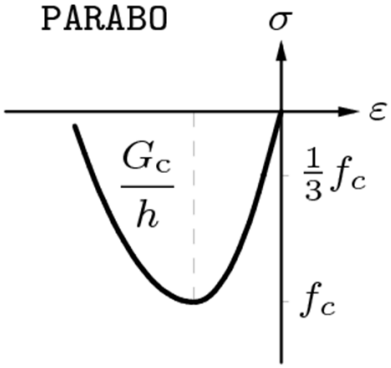

(b)

Figure 7: Stress-strain diagrams adopted for the behavior of masonry in a) tension and b) compression 


\section{CALIBRATION}

The described model was implemented with the purpose of including all the complexities of the existing building in order to inspect its global structural and dynamic behavior. To this end, the model construction had to face two challenges: 1) the choice of an appropriate modeling strategy for each structural element, 2) the selection of appropriate mechanical characteristics of the materials involved. Both were overcome by validating the adopted modeling strategies with the results of the OMA introduced in Sect. 2, and by calibrating the relevant elastic mechanical characteristics tuning the natural frequencies of the model with the ones measured in the church. In particular, the process of validation of the modeling strategies consisted of an iterative procedure in which each strategy was inspected by eigenvalue analysis and comparison with the modal parameters obtained with the OMA. On the other hand, due to the great relevance of masonry elastic properties in the definition of the stiffness of the system, its elastic Young's modulus was calibrated to tune the first natural frequency of the FEM model as equal to the first natural frequency of the real structure. This section illustrates the processes that allowed the definition of the final model on which perform the structural analyses ([10], [12]).

\subsection{Calibration of the modal shape}

The results of the analysis of the first tentative model evidenced a first global modal shape which mainly involved the transversal deformation of the western section of the transept and a relatively small deformation of the front and the back parts of the church. Even if not
corresponding to the experimental results, such a response was expected to some extent. In
fact, the difference in the geometrical stiffnesses provided by the western part of the transept,
laying partially on the top of the colonnade, and the eastern part, represented by the tyo L-
shaped walls of the transept and the apse, is evident. Conversely, the absence of mobilization of the back portion of the church, witnessing higher stiffness with respect to the main body,

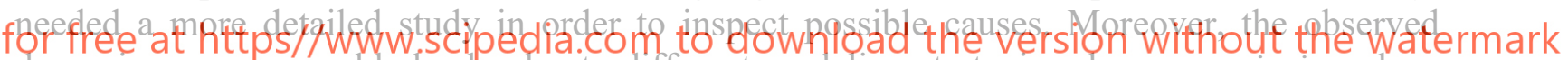
dynamic response could also be due to different modeling strategies chosen a priori, such as the choice of the boundary conditions to apply to the foundation system and the exclusion of the mass and stiffness contribution given by the roofing system, suppressed in the first tentative model.

For the above-mentioned reasons some alternative models were prepared in order to inspect: a) the influence of the geometrical and mechanical stiffness of the back part, b) the influence of the modeling strategies to apply to the foundation system, c) the influence of the modeling strategies to apply to the roofing system.

\subsubsection{Geometrical and mechanical stiffness of the back part}

In order to inspect the structural relevance of the rear portion of the building, a partial model was developed by extracting the back portion from the original model (MG_01). This step allowed to highlight, firstly, the great geometrical stiffness of this portion, witnessed by the lack of global modes for frequencies of the order of $10 \mathrm{~Hz}$ (Figure 8). Secondly, it was noticed that the modal shape of the church portion is still governed by the L-shaped walls of the transept which do not allow the development of proper translational modal shapes. Lastly, as expected, the layout of the timber frames scarcely influences the modal shapes of the sub- 
structures, as evidenced in the analysis of a model with the complete absence of timber elements (MG_02), while having relevance in the modal frequencies as evidenced in Table 2.

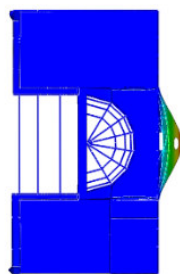

$\# 1$ $4.07 \mathrm{~Hz}$

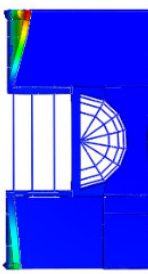

\#2

$5.32 \mathrm{~Hz}$

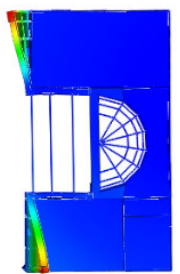

\#3

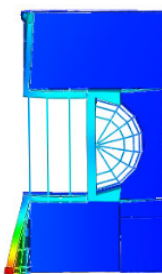

\#4

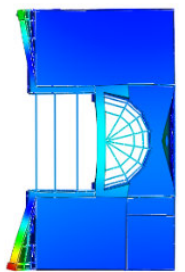

\#5

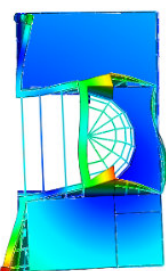

\#6

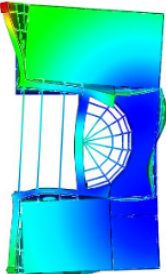

\#7

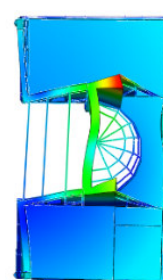

\#8

Figure 8: First eight modal shapes of the $\mathrm{MG}_{-} 01$

Table 2: Frequency comparison of the models $\mathrm{MG}_{-} 01$ and $\mathrm{MG}_{-} 02$

\begin{tabular}{cccc} 
Mode & \multicolumn{2}{c}{ Frequency [Hz] } & Decrease \\
\cline { 2 - 3 } & MG_01 & MG_02 & [\%] \\
\hline 1 & 4.071 & 3.294 & 19.1 \\
\hline 2 & 5.320 & 4.926 & 7.4 \\
\hline 3 & 5.378 & 5.039 & 6.3 \\
\hline
\end{tabular}

Besides, the structural stiffness of the rear portion was inspected also with a global model in which the back wall of the canonical house is weakened in various ways: suppression of the central section of the canonical house (MG_03), suppression of the masonry arch at the top of the apse ( $\mathrm{MG}_{-}$04), and combination of the two scenarios ( $M G_{-}$05). In fact, the of stiffness of a long wall such as the back wall of the canonical house, along w
dome and arch, is relevant to the definition of the global behavior. Conversely, evidenced that the translational response of the structure is governed by the high stiffuess of the western branch of the transept and by the higher deformability of the eastern branch and the naves, so the back wall and apsidal section stiffness contribution.is irrelevant (Figure 9). for free at https/yww.scipedia.com to download the version without the watermark as original in the final model and further calibration strategies were adopted for the modal shapes.

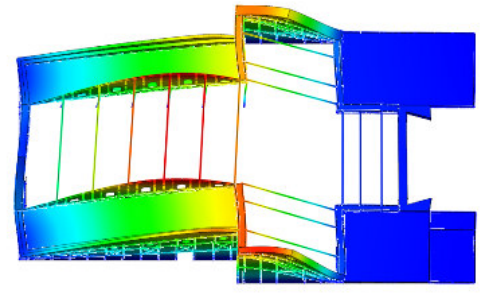

$\# 1(\mathrm{f}=3.01 \mathrm{~Hz})$

a)



$\# 1(\mathrm{f}=3.02 \mathrm{~Hz})$

b)

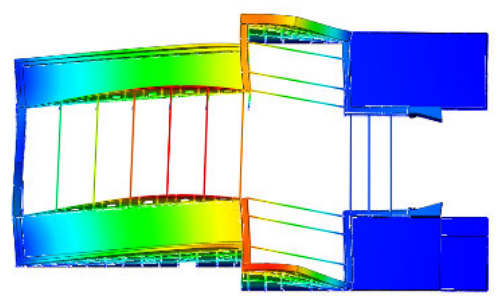

$\# 1(\mathrm{f}=3.01 \mathrm{~Hz})$

c)

Figure 9: First global modal shapes of the models a) MG_03, b) MG_04, c) MG_05

\subsubsection{Foundation stiffness influence}

As mentioned above, the modeling strategy for the foundations was the adoption of perfectly rigid boundary conditions. It is well known that in a realistic representation of the 
soil-structure interaction some movements are expected. Some analyses were performed (MF_01), by modeling the soil-structure interaction through interface elements with assigned limited stiffness in the vertical direction, according to the Winkler's theory of the elastic soil. It is worth highlighting that such a refined model should be supported by an appropriate level of knowledge about the soil characteristics. In the present case, it was adopted in the scope of inspecting the sensitivity of the dynamic response to these parameters and the need of improving their knowledge. For this reason, the elastic modulus of the soil was esteemed with the literature values $(\mathrm{E}=120 \mathrm{MPa})$, considering the edometric modulus equal to 1.15 times the elastic one.

Moreover, since the eigenvalue analyses described so far never involved the translational response of the back portion of the church, an attempt of mobilizing it was carried out by significantly decreasing the mechanical stiffness of the material representing the masonry walls of the canonical house and the stiffness constant of the interface elements below the canonical house (MF_02), also considering optimal characteristics of these two parameters in the main body portion of the church (MF 03). As observed in Figure 10, the influence of these strategies with respect to the dynamic behavior of the church has more relevance in the natural frequencies of the structure rather than in the modal shapes. For this reason, and due to the limited knowledge of the soil characteristics, the interface modeling of the foundations was discarded, and the same value of Young's modulus was kept for all the masonries.
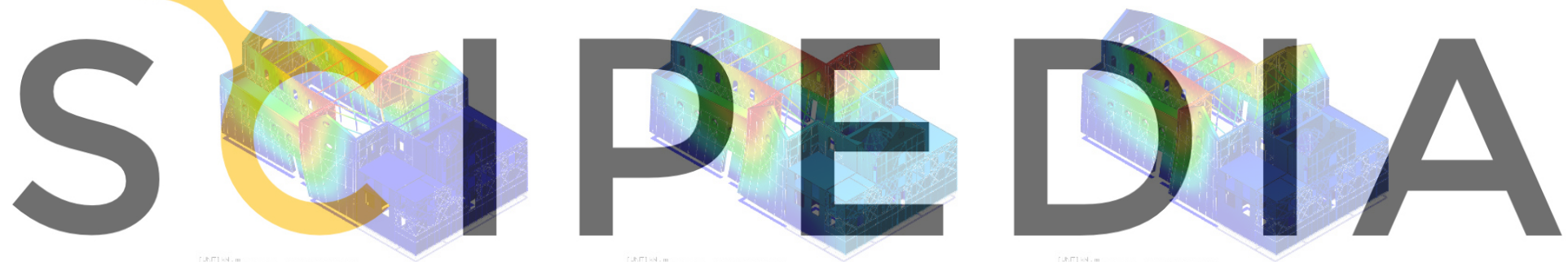

Register for free at (f)

Figure 10: First global modal shapes of the models a) MF_01, b) MF_02, c) MF_03

\subsubsection{Roof mass and stiffness influence}

With the aim of reducing the model complexity and size, it was initially decided not to include the roofing system in the numerical model, due to the relatively small mass of the timber roof and the relatively high deformability of the attic floor slab. This approach included two simplifications which have great impact in the dynamic response of the structure: a) the suppression of the participating mass of the roof located at the top of the construction; b) the suppression of the stiffness contribution provided at the attic level by the attic floor slab and the roof trusses, which, in particular, enable the redistribution of the horizontal loads at the top of the church walls in case of earthquake.

A further development of an additional model (MR 01), allowed to minimize the error connected to these simplifications, in which the roof mass was applied at the top of the structure as a distributed mass and the timber ties of the roof trusses were simulated with transversal ties over the central nave and the transept. Moreover, more modifications were inspected by inserting additional ties across the cross-shaft (MR_02). The inclusion of these 
modifications in the final model allowed a better approximation of the numerical model to the experimental results and to the expected dynamic behavior (Figure 11).

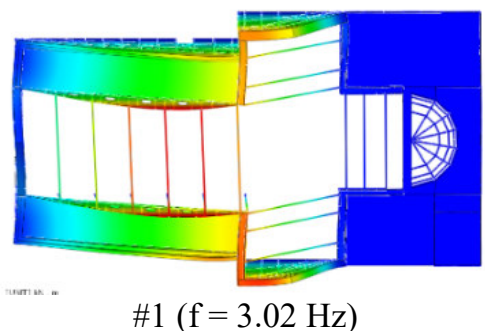

a)

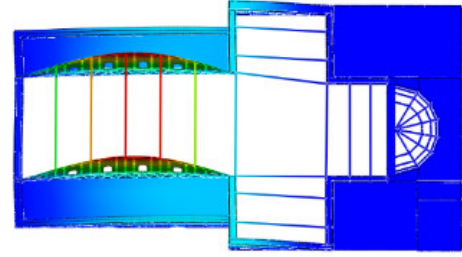

$\# 1(\mathrm{f}=2.16 \mathrm{~Hz})$

b)

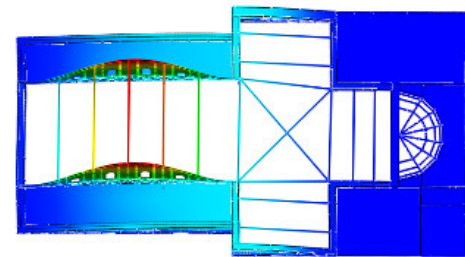

$\# 1(\mathrm{f}=2.54 \mathrm{~Hz})$

c)

Figure 11: First global modal shapes in a) the first tentative model, b) MR_01, c) MR_02

However, the modal shapes obtained still hardly correspond to the experimental ones. In fact, the modifications implemented allow a more coherent transversal behavior of the naves, the transept and the back portion, but a relevant deformation of the longitudinal walls of the central nave in the transversal out-of-plane direction is also detected. More studies were performed in order to try to limit the latter behavior by incrementing significantly the stiffness at the roof level, but no significant improvements were found. Conversely, it can be observed that the performed test setup was not able to catch this behavior since no accelerometers were placed at the top-middle location of the second-story walls of the central nave (Figure 4). Hence, the experimental results can only be compared with a partial numerical model in which the upper walls of the central nave are removed, which provide a good shape approximation indeed (Figure 12).

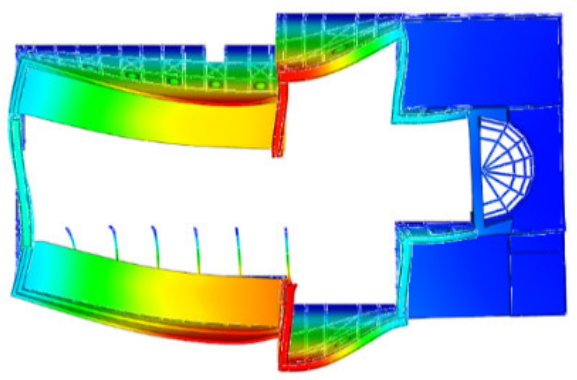

Figure 12: First modal shape of the final model (MR_02) removing the upper walls of the central nave

\subsection{Calibration of the modal frequency}

Further, the calibration of the elastic properties of the masonry material was carried out, according to [24], through the adaptation of the first numerical global frequency to the first experimental one. The iterative minimization procedure of error on the first frequency led to the estimation of a Young's modulus of the masonry material of $887 \mathrm{MPa}$, from a first tentative value of $920 \mathrm{MPa}$. Subsequently, the Modal Assurance Criterion (MAC) was calculated to evaluate the modal shapes of the first three modes, leading to a MAC $=0.74$ for the first mode and irrelevant MAC valued for the sequent. It must be pointed out that optimum correlations are represented by $\mathrm{MAC} \geq 0.9$, good correlations by $0.8 \leq \mathrm{MAC}<0.9$ and acceptable correlations by $0.7 \leq \mathrm{MAC}<0.8$. MAC values lower than 0.7 are not considered 
acceptable for matched modes [24]. The present case is assessed in an acceptable range of values, which was expected since many issues were encountered during the OMA and the calibration of the modal shape.

\section{DISCUSSION AND CONCLUSIONS}

This paper discusses the methodology applied to an historical building complex in shape, materials and constructive technologies, in order to identify the dynamic properties of the structure and implement a numerical model able to catch its seismic behavior. After the execution of ambient vibration tests on the existing church and the performance of an Operational Modal Analysis to post-process the results, some eigenvalues analyses were performed on alternative versions of the FEM model in order to inspect the influence of the various modeling strategies and mechanical characteristics applied.

In conclusion, it can be observed that the several attempts explored to find a better agreement between the numerical and experimental models well testify the challenging complexity of the structural typology of the church. It was highlighted that the level of knowledge of the structural details and the materials highly influenced the definition of the modeling strategies adopted for the numerical model in the scope of inspecting their relevance in the structural behavior of the building. In this sense, it was observed that simplifications adopted at the beginning of the modeling phase highly influenced the response. Therefore, the modeling strategy and simplifications in the modeling of a complex structure should be taken with great care. The results of the performed ambient vibration tests revealed to be in some cases incomplete in the description of the complex dynamic response of the church, underling the usefulness of preliminary numerical models for defining measurement setup in dynamic identification tests for such complex structures as the Santa Maria Maddalena Church.

Acknowledgements. This work was carried out in the frame of the Advanced Master in Structural Analysis of Historical Constructions and Monuments (SAHC) and partially sponsored by the Italian Civil Protection, through the RELUIS Project - WP4: MAppe di Rischio e Scenari di danno sismico (MARS) (2020). The mentioned in-situ analyses were performed under the commission of the Campania Regional Directorate for Cultural Heritage (MiBACT).

\section{REFERENCES}

[1] Clementi, F., Gazzani, V., Poiani, M. and Lenci, S. Assessment of seismic behaviour of heritage masonry buildings using numerical modelling. Journal of Building Engineering (2016) 8:29-47.

[2] Betti, M. and Vignoli, A. Numerical assessment of the static and seismic behaviour of the basilica of Santa Maria all'Impruneta (Italy). Construction and Building Materials (2011) 25(12):4308-4324.

[3] Formisano, A. and Marzo, A. Simplified and refined methods for seismic vulnerability assessment and retrofitting of an Italian cultural heritage masonry building. Computers and Structures (2017) 180:13-26.

[4] Mendes, N. and Lourenço, P.B. Seismic assessment of masonry Gaioleiro buildings in Lisbon, Portugal. Journal of Earthquake Engineering (2010) 14(1):80-101.

[5] Ciocci, M.P., Sharma, S. and Lourenço, P.B. Engineering simulations of a super-complex cultural heritage building: Ica Cathedral in Peru. Meccanica (2018) 53(7):1931-1958.

[6] Asteris, P.G., Chronopoulos, M.P., Chrysostomou, C.Z., Varum, H., Plevris, V., Kyriakides, N. and Silva, V. Seismic vulnerability assessment of historical masonry structural systems. Engineering Structures (2014) 62-63:118-134.

[7] Galassi, S. and Ruggieri, N. Stability and Stiffness Contribution of the masonry in the Borbone Anti- 
seismic System. 9th International Masonry Conference 2014 Guimarães (2014) 1-9.

[8] Salerno, G., Geremia, F., Pagano, E., Zampilli, M., Ruggieri, N. and Stellacci, S. The Masonry Timber Framed Load Bearing Structure of "Baraccato" System: A Numerical Model. In: H. Cruz et al. (Eds.): Historical Earthquake-Resistant Timber Frames in the Mediterranean Area, Springer Netherlands (2015), pp. 205-2013.

[9] Poletti, E., Vasconcelos, G., Lourenço, P.B. and Ciocci, M.P. Numerical Approaches for the Analysis of Timber Frame Walls. In: H. Cruz et al. (Eds.): Historical Earthquake-Resistant Timber Frames in the Mediterranean Area, Springer Netherlands (2015), pp. 183-192.

[10] Di Napoli, B. Modelling and safety assessment of the Church of Santa Maria Maddalena, Ischia, Italy. Universidade do Minho (2019).

[11] Casapulla, C., Ceroni, F., Rainieri, C., Argiento, L.U., Arcamone, P., Fabbrocino, G. and Carducci, V. Structural assessment of Santa Maria Maddalena church in Ischia (Italy) by experimental modal analysis under operational conditions. In: M. Papadrakakis and M. Fragiadakis (Eds.): Computational Methods in Structural Dynamics and Earthquake Engineering (COMPDYN 2019), ECCOMAS Bookseries (2019), pp. 24-26.

[12] Di Napoli, B., Ciocci, M.P., Celano, T., Argiento, L.U., Casapulla, C. and Lourenço, P.B. Seismic behaviour of a mixed iron-masonry church: Santa Maria Maddalena, Ischia (Italy). Engineering and Computational Mechanics (2020) (under review)

[13] Ruggieri, N. and Tampone, G. Historical Earthquake-Resistant Timber Frames in the Mediterranean Area. In: N. Ruggieri, R. Zinno and G. Tampone (Eds.): Historical Earthquake-Resistant Timber Frames in the Mediterranean Area. Springer Cham (2015).

[14] ARTeMIS Modal v3.5.1.1. Ambient Response Testing and Modal Identification Software. (2018).

[15] DIANA FEA BV. DIANA Finite Element Analysis User's Manual Release 10.3. DIANA FEA BV (2019).

[16] Li, Y. and Barbič, J. Stable orthotropic materials. In: V. Koltun and E. Sifakis (Eds.): ACM/Eurographics Symposium on Computer Animation, The Eurographic Association (2014), pp. 41-46.

[17] C.S.LL.PP. Circolare 21 gennaio 2019 n. 7 Istruzioni per l'applicazione dell'aggiornamento delle "Norme Tecniche per le Costruzioni” di cui al D.M. 17/01/2018, Consiglio Superiore dei Lavori Pubblici (2018).

[18] Bussell, M.N. Appraisal of existing iron and steel structures. Steel Construction Institute, (1997).

[19] EC-Standards. EN 338:2003 - Structural timber - Strength classes (updated 2009). Ente Nazionale Italiano di Unificazione UNI (2003).

[20] Sousa, H.S., Branco, J.M. and Lourenço, P.B. Characterization of cross sections from old chestnut beams weakened by decay. International Journal of Cultural Heritage (2014) 8(3):436-451.

[21] MIT. Decreto Ministeriale 17 gennaio 2018 n. 8 Aggiornamento delle «Norme tecniche per le costruzioni»., Ministero delle Infrastrutture e dei Trasporti (2018).

[22] Calderoni, B., Cordasco, E.A., Guerriero, L., Lenza, P. and Manfredi, G. Mechanical Behaviour of PostMedieval Tuff masonry of the Naples Area. Journal of the Intenational Masonry Society (2009) 21:85-96.

[23] Lourenço, P.B. Structural masonry analysis: recent developments and prospects. In: University of Newcastle (Australia) (Ed.): Proceedings of the 14th international brick \& block masonry conference, (2008), Issues: 17-20, pp. 1341-1356.

[24] Mendes, N. Seismic assessment of ancient masonry buildings : Shaking table tests and numerical analysis. PhD Thesis, Universidade do Minho (2012). 